\title{
Research on the Factors Influencing Regional Development Differences of the Financial Industry in Yunnan Province
}

\author{
Meijuan Li \\ School of Economics and Management \\ Yunnan Normal University \\ Kunming 650092, China
}

\author{
Yuluan Chen \\ School of Economics and Management \\ Yunnan Normal University \\ Kunming 650092, China
}

\begin{abstract}
To evaluate the regional financial development differences in Yunnan, this paper summarizes its present situation from regional financial aggregates, regional financial structure and regional financial efficiency, we use factor analysis and cluster analysis to analyze the main factors that affect the regional financial development differences in Yunnan. Our results show that the main factors are the economic basis and human capital levels. GDP per capita is the key factor that influences the development difference of financial industry in Yunnan Province. Kunming has a better economic base and economic efficiency, and the demand for the financial system is greater than other states. The followed factors are the level of investment and financing, the level of regional informatization and geographical location. Kunming has a good foundation in geographical location, investment and financing level and informatization level, it has obvious advantages on the level of financial development, which leads to the unilateral flow of talent and exacerbates the gap of financial development between states. These results are of great clinical significance in promoting the coordinative sustainable development of regional economic and finance in Yunnan.
\end{abstract}

Keywords-Regional Finance; Development Differences; Influencing factors; Factor Analysis

\section{THE PRESENT SITUATION OF REGIONAL DEVELOPMENT DIFFERENCES IN THE FINANCIAL INDUSTRY OF YUNNAN PROVINCE}

\section{A. Differences of regional financial aggregate}

We mainly use the sum of the deposits and loans of the financial institutions to measure the financial aggregates of each state [1]. As can be seen from the table 1, the sum of deposits and loans in each state has increased from the 2010 to 2015 , but the gap is quite obvious. The sum of deposits and loans is the highest in Kunming, reaching 2379.077 billion yuan in 2015 while the lowest was Nujiang. In 2015,it was 27.802 billion yuan, only $1.2 \%$ as much as Kunming. Compared with 2010,the deposits and loans in Kunming increased by 1010.269 billion yuan in 2015 , and the increase was much higher than the total amount of other states. Besides Kunming, the states with a higher sum of deposits and loans include Qujing, Honghe, Dali and Yuxi. With the exception of Nujiang, Diqing, Xishuangbanna, Dehong, Lincang and
Lijiang also have a lower deposit and loans. Their annual deposit and loans are below100 billion yuan.

\section{B. Differences of regional financial structure}

We mainly use financial interrelations rate (FIR) to measure the difference of regional financial structure. Western scholars represented by Mackinnon mainly use the ratio of M2 to GDP to express FDI, but some cities in Yunnan lack the data of financial assets and M2, so, the ratio of M2 to GDP can not be used directly to represent FIR [2]. In view of the fact that many scholars in China use the sum of deposits and loans in financial institutions to measure the financial assets, this paper refers to their research results which FIR equal financial institutions deposits plus financial institutions loans divided by GDP [3].

In general, from 2010 to 2015, The FIR of the states showed a growth trend, but the growth rate of different states are not the same. There are growth in some states, while their FIR value is still very low, such as Yuxi, Lincang, Chuxiong and Qujing, which shows that the financial deepening degrees of these states are weak, even exist financial repression (Table 2).The FIR of Kunming is the highest, which is over 5, indicating that Kunming has the deepest financial deepening. The FIR of Lijiang is second only to Kunming, indicating that the degree of financial deepening of Lijiang in Yunnan Province is still very front.

\section{Differences of regional financial efficiency}

We mainly measure financial efficiency from the growth rate of deposit balance at the end of the year in financial institution [4].

Table 3 reflects the changes of the growth rate of deposit balance of financial institutions in each states of Yunnan from 2011 to 2015.As we can see, the overall growth rate from 2011 to 2013 is relatively fast, and the growth rate from 2014 to 2015 has slowed down. The rapid growth of the total balance of deposits makes the overall growth rate slower, which is also a feature of the new stage of financial development. Each state has achieved growth every year, among which Baoshan and Wenshan are the most obvious. 
TABLE I THE TOTAL DEPOSITS AND LOANS OF FINANCIAL INSTITUTIONS IN EACH STATES OF YUNNAN PROVINCE

\begin{tabular}{|c|c|c|c|c|c|c|}
\hline State/year & 2010 & 2011 & 2012 & 2013 & 2014 & 2015 \\
\hline Kunming & 13688.08 & 14842.94 & 17001.95 & 19233.99 & 20783.54 & 23790.77 \\
\hline Qujing & 1646.57 & 1914.21 & 2264.49 & 2621.34 & 2838.04 & 3094.5 \\
\hline Yuxi & 1281.67 & 1459.2 & 1633.63 & 1837.59 & 1972.76 & 2168.56 \\
\hline Baoshan & 575.65 & 712.3 & 795.43 & 924.53 & 1085.62 & 1325.92 \\
\hline Zhaotong & 806.69 & 975.25 & 1189.08 & 1321.3 & 1577.06 & 1825.76 \\
\hline Lijiang & 491.53 & 599.35 & 720.78 & 830.34 & 901.39 & 967.19 \\
\hline Puer & 595.91 & 699.44 & 819.27 & 999.25 & 1142.68 & 1308.85 \\
\hline Lincang & 413.59 & 518.12 & 616.06 & 725.83 & 822.32 & 942.66 \\
\hline Chuxiong & 694.2 & 806.27 & 938.23 & 1133.59 & 1301.15 & 1499.16 \\
\hline Honghe & 1072.93 & 1582.49 & 1819.82 & 2093.77 & 2392.64 & 2624.69 \\
\hline Wenshan & 659.21 & 773.65 & 924.82 & 1087.34 & 1231.54 & 1454.13 \\
\hline Xishuangbanna & 401.878 & 488.04 & 554.46 & 644.55 & 720.63 & 797.96 \\
\hline Dali & 969.17 & 1198.03 & 1423.23 & 1719.88 & 1969.61 & 2223.45 \\
\hline Dehong & 452.74 & 547.64 & 621.06 & 711.64 & 773.99 & 919.96 \\
\hline Nujiang & 143.02 & 154.03 & 178.31 & 210.17 & 243.533 & 278.02 \\
\hline Diqing & 205.91 & 250.95 & 299.24 & 376.86 & 408.38 & 468.16 \\
\hline
\end{tabular}

TABLE II FINANCIAL INTERRELATIONS RATIO VALUES IN EACH STATES OF YUNNAN

\begin{tabular}{|c|c|c|c|c|c|c|}
\hline State/year & 2010 & 2011 & 2012 & 2013 & 2014 & 2015 \\
\hline Kunming & 6.46 & 5.91 & 5.65 & 5.63 & 5.60 & 6.00 \\
\hline Qujing & 1.64 & 1.58 & 1.62 & 1.65 & 1.83 & 1.90 \\
\hline Yuxi & 1.74 & 1.66 & 1.63 & 1.67 & 1.67 & 1.74 \\
\hline Baoshan & 2.78 & 2.20 & 2.04 & 2.06 & 2.16 & 2.40 \\
\hline Zhaotong & 2.12 & 2.10 & 2.14 & 2.08 & 2.36 & 2.58 \\
\hline Lijiang & 3.42 & 3.36 & 3.40 & 3.34 & 3.34 & 3.34 \\
\hline Puer & 2.40 & 2.32 & 2.23 & 2.35 & 2.40 & 2.55 \\
\hline Lincang & 1.91 & 1.90 & 1.75 & 1.74 & 1.77 & 1.88 \\
\hline Chuxiong & 1.72 & 1.67 & 1.65 & 1.79 & 1.84 & 1.96 \\
\hline Honghe & 1.65 & 2.03 & 2.01 & 2.04 & 2.12 & 2.15 \\
\hline Wenshan & 2.00 & 1.93 & 1.93 & 1.96 & 2.00 & 2.17 \\
\hline Xishuangbanna & 2.51 & 2.47 & 2.38 & 2.37 & 2.35 & 2.38 \\
\hline Dali & 2.04 & 2.11 & 2.12 & 2.26 & 2.37 & 2.47 \\
\hline Dehong & 3.22 & 3.18 & 3.09 & 3.08 & 3.13 & 3.15 \\
\hline Nujiang & 2.61 & 2.38 & 2.38 & 2.46 & 2.43 & 2.46 \\
\hline Diqing & 2.67 & 2.60 & 2.63 & 2.87 & 2.77 & 2.91 \\
\hline
\end{tabular}

TABLE III THE GROWTH RATE OF DEPOSIT BALANCE OF FINANCIAL INSTITUTIONS IN EACH STATE OF YUNNAN

\begin{tabular}{|c|c|c|c|c|c|}
\hline Region/year & 2011 & 2012 & 2013 & 2014 & 2015 \\
\hline Yunnan & $12.67 \%$ & $14.52 \%$ & $13.17 \%$ & $7.37 \%$ & $10.77 \%$ \\
\hline Kunming & $10.79 \%$ & $14.50 \%$ & $12.38 \%$ & $4.70 \%$ & $10.70 \%$ \\
\hline Qujing & $13.87 \%$ & $15.94 \%$ & $12.45 \%$ & $5.72 \%$ & $7.14 \%$ \\
\hline Yuxi & $11.07 \%$ & $8.40 \%$ & $11.29 \%$ & $5.56 \%$ & $9.58 \%$ \\
\hline
\end{tabular}




\begin{tabular}{|c|c|c|c|c|c|}
\hline \multicolumn{7}{|c|}{ Table III, cont. } \\
\hline Baoshan & $16.56 \%$ & $13.94 \%$ & $13.06 \%$ & $12.92 \%$ & $17.65 \%$ \\
\hline Zhaotong & $16.03 \%$ & $19.35 \%$ & $10.50 \%$ & $17.70 \%$ & $13.71 \%$ \\
\hline Lijiang & $14.68 \%$ & $16.52 \%$ & $13.61 \%$ & $6.72 \%$ & $6.23 \%$ \\
\hline Puer & $14.12 \%$ & $14.03 \%$ & $17.96 \%$ & $9.94 \%$ & $12.30 \%$ \\
\hline Lincang & $18.29 \%$ & $13.44 \%$ & $14.26 \%$ & $9.04 \%$ & $12.84 \%$ \\
\hline Chuxiong & $13.24 \%$ & $14.03 \%$ & $16.66 \%$ & $12.10 \%$ & $12.33 \%$ \\
\hline Honghe & $12.32 \%$ & $12.98 \%$ & $12.27 \%$ & $11.70 \%$ & $7.97 \%$ \\
\hline Wenshan & $17.74 \%$ & $17.49 \%$ & $15.82 \%$ & $10.56 \%$ & $13.59 \%$ \\
\hline Xishuangbanna & $19.90 \%$ & $11.36 \%$ & $13.13 \%$ & $8.15 \%$ & $6.19 \%$ \\
\hline Dali & $17.37 \%$ & $19.36 \%$ & $17.72 \%$ & $10.36 \%$ & $10.38 \%$ \\
\hline Dehong & $17.59 \%$ & $7.92 \%$ & $11.87 \%$ & $12.49 \%$ & $17.06 \%$ \\
\hline Nujiang & $13.92 \%$ & $11.86 \%$ & $16.07 \%$ & $15.91 \%$ & $10.11 \%$ \\
\hline Diqing & $16.18 \%$ & $17.84 \%$ & $24.90 \%$ & $10.67 \%$ & $14.01 \%$ \\
\hline
\end{tabular}

\section{FACTORS OF REGIONAL DEVELOPMENT DIFFERENCES IN FINANCIAL INDUSTRY}

\section{A. Economic basis}

Economic basis is the key determinant to the development of the financial industry. If there is no good economic basis as a guarantee, the financial vitality and driving force will not be able to display. The two sides are mutually reinforcing. The

\section{B. Geographical location}

The development of the financial industry is inseparable from a good geographical location, so we will use the geographical location as the assessment indicators, many financial development areas, such as Shanghai, New York, are international ports, and have an very frequent transactions, which will provide a prerequisite for the development of the financial [5], while the opening of the Shanghai-Kunming high-speed railway will inject new economic power in Yunnan Province to promote the development of regional characteristics of the financial industry. The indicators of geographic location will be denoted the balance of deposits in the state financial institutions.

\section{Investment and financing level}

The investment and financing level reflects the degree of economic and financial development in a region, which is an important factor that influences the development of financial regional development [6]. The development of the financial industry can not be separated from the development of investment and financing activities. Finance is the financing of the financial industry. It can be said that the financial industry is closely related to investment and financing activities from its origin. Investment and financing level will profoundly affect the development of the financial industry. We use the total amount of financial institutions' loan balances in each state as the measure indicator. economic development is the guarantee of financial development, the development of finance in turn promotes economic development better. Economic basis is the most fundamental determinants of financial regional development.According to international practices, the measure indicator of economic basis is used mainly region's GDP, but taking into account the state of Yunnan Province that the population base is not the same, so we use the per capita GDP to measure the economic base of each state.

\section{Human capital}

The development of the financial industry is inseparable from the excellent human capital, the development of the financial industry requires the injection of high-quality compound talents, and the level of higher education in the developed areas of China's financial industry is also the national leader, so this important indicator will be assessed the financial development differences in various states of Yunnan Province. Human capital reflects the region's economic development to attract talent, financial development is required mostly of human capital, which is reflected the region's financial development level. The indicator of human capital will be indicated by the average wage of employees in each state.

\section{E. Regional information level}

Information capital is also the financial industry's recent hot spots, Internet finance has attracted the government and the people's attention in recent years, at the same time, the rapid development of the financial industry is inseparable from the effective information market, the regional information level determines the height of the development of the financial industry to a large extent. The professionalization of finance is inseparable from the rapid development of highly developed information capital market. The regional information level will be measured as the number of internet users in each state of Yunnan Province. 


\section{F. Transportation conditions}

Transportation facilities are also necessary to the development of the financial industry, so the reference to the financial development indicators, we use the transportation conditions into the assessment indicators, which compares the regional development differences of the financial industry in Yunnan Province. The state's vehicles will be used as the measurement indicators of the transportation condition.

\section{G. Technology level}

The development of finance is inseparable from the improvement of science and technology level. The high-tech level will provide the most direct technical transportation for regional development differences of the financial industry. The financial indicators of the level of science and technology will use the number of the people who worked in the natural science institutions in the state that engaged the scientific and technical to express.

\section{THE EMPIRICAL ANALYSIS OF THE FACTORS INFLUENCING REGIONAL DEVELOPMENT DIFFERENCES OF FINANCIAL INDUSTRY IN YUNNAN PROVINCE}

We use the relevant indicators' datas of the influencing factors in 2015, and analyzes the regional development differences of financial industry in Yunnan by using the factor analysis, principal component analysis and cluster analysis. The reduction and simplification of the original data of the relevant indexes are classified into the same class, and the correlation between the different categories of variables is low, and the extracted public factor is used to explain the regional financial development level. The test of KMO and Bartlett of Table 5 is obtained using the relevant indicators of Table 4 and their corresponding data.

TABLE IV KMO AND BARTLETT TEST

\begin{tabular}{|c|c|c|}
\hline \multicolumn{2}{|c|}{$\begin{array}{c}\text { Samples are sufficient to measure the } \\
\text { Kaiser-Meyer-Olkin metric }\end{array}$} & .820 \\
\hline \multirow{3}{*}{$\begin{array}{c}\text { Bartlett's Spherical } \\
\text { Test }\end{array}$} & $\begin{array}{c}\text { Approximate } \\
\text { card side }\end{array}$ & 183.511 \\
\cline { 2 - 3 } & $\mathrm{df}$ & 21 \\
\cline { 2 - 3 } & Sig. & .000 \\
\hline
\end{tabular}

From Table 5 we can see: KMO value of 0.820 , Bartlett statistical significance of the probability is 0.000 , obviously less than its critical value of $1 \%$, which can make the factor analysis.

TABLE V THE TOTAL VARIANCE OF EXPLAINS

\begin{tabular}{|c|c|c|c|c|c|}
\hline \multirow{2}{*}{ Ingredients } & \multicolumn{3}{|c|}{ Initial eigenvalue } & \multicolumn{2}{c|}{ Extract squares and load } \\
\cline { 2 - 6 } & total & Variance\% & Accumulated\% & total & Variance\% \\
\hline 1 & 5.257 & 75.097 & 75.097 & 5.257 & 75.097 \\
\hline 2 & 1.159 & 16.558 & 91.655 & 1.159 & 16.558 \\
\hline 3 & .398 & 5.689 & 97.344 & .398 & 5.689 \\
\hline 4 & .138 & 1.970 & 99.314 & & \\
\hline 5 & .039 & .558 & 99.872 & & \\
\hline 6 & .009 & .122 & 99.994 & & \\
\hline 7 & .000 & .006 & 100.000 & & \\
\hline
\end{tabular}

TABLE VI THE TOTAL VARIANCE OF EXPLAINS

\begin{tabular}{|c|c|c|c|c|}
\hline \multirow{2}{*}{ Ingredients } & $\begin{array}{c}\text { Extract squares and } \\
\text { load }\end{array}$ & \multicolumn{3}{|c|}{ Rotate squares and load } \\
\cline { 2 - 5 } & Accumulated\% & total & Variance\% & Accumulated\% \\
\hline 1 & 75.097 & 4.466 & 63.795 & 63.795 \\
\hline 2 & 91.655 & 1.214 & 17.342 & 81.137 \\
\hline 3 & 97.344 & 1.134 & 16.207 & 97.344 \\
\hline
\end{tabular}

Table 6 shows the eigenvalues of the principal components that reflects the level of financial development. The cumulative contribution rate of the composite factor is $97.344 \%$, which indicates that the comprehensive factor can well reflect most of the economic information and also can be maintained independence very well between each other.

Rotate the factors to obtain the corresponding factor load matrix, see at Table 7 .

TABLE VII ROTATE THE COMPOSITION MATRIX A

\begin{tabular}{|c|c|c|c|}
\hline \multirow{2}{*}{} & \multicolumn{3}{|c|}{ Ingredients } \\
\cline { 2 - 4 } & 1 & 2 & 3 \\
\hline Per capita GDP & .414 & .278 & .865 \\
\hline Per capita wage & .103 & .963 & .197 \\
\hline Financial institution deposit balance & .941 & .136 & .297 \\
\hline
\end{tabular}




\begin{tabular}{|c|c|c|c|}
\hline \multicolumn{4}{|c|}{ Table VII, cont. } \\
\hline Financial institution loan balance & .941 & .163 & .285 \\
\hline Number of Internet users & .945 & .200 & .227 \\
\hline Area civilian vehicle ownership & .875 & -.282 & .270 \\
\hline Technical Personnel in Natural Science & .924 & .214 & .231 \\
\hline
\end{tabular}

TABLE VIII ROTATE THE COMPOSITION MATRIX A

\begin{tabular}{|c|c|c|c|}
\hline & First echelon & Second echelon & Third echelon \\
\hline Influencing factors & $\begin{array}{c}\text { Economic base, } \\
\text { human capital }\end{array}$ & $\begin{array}{c}\text { Investment and } \\
\text { financing level, } \\
\text { regional information, } \\
\text { geographical location }\end{array}$ & $\begin{array}{c}\text { Scientific and technological } \\
\text { level, transportation conditions }\end{array}$ \\
\hline
\end{tabular}

It can be found from Table 9 that the first echelon is composed of two factors: economic base and human capital level, which shows that GDP per capita is the key factor that influences the development difference of financial industry in Yunnan Province. The development of economic development will lead to the flourish of financial industry. Kunming has a better economic base and economic efficiency, and the demand for the financial system is greater than other states so that its financial development scale and structure are higher than other, all kinds of financial institutions are mostly gathered in Kunming. And it needs to focus on attracting and digging talent at the same time, the financial industry is a sophisticated industry, which can not do well without highquality compound talents to join. Financial industry due to the particularity of the business, its business operations, technology development and other personnel of the overall quality should be higher than other industries. Therefore, human capital is the financial industry's most important asset, the level of financial practitioners education has a crucial role on the competitiveness of the financial industry to a large extent, but the local government that give the financial practitioners different education, which leads to the difference of the financial development.

In the second tier of the level are investment financing level, information degree and geographical location. Some states have been low level of investment and financing level for a long time, infrastructure is not perfect, a big difference on Internet users, which results in a large gap in the level of financial development and large differences in financial costs. Kunming has a good foundation in geographical location, investment and financing level and informatization level, it has obvious advantages on the level of financial development, which leads to the unilateral flow of talent and exacerbates the gap of financial development between states. In the third echelon of the level are science technology level and transportation conditions, indicating that the impact of these factors on the development difference of financial industry in each states is lower than other factors.

\section{SUGGESTIONS}

A. Promote the allocation of labor, strengthen human capital investment

With the development of human society and technology, human capital investment has become major driving force of financial development. We need to realize that population is not equivalent to human capital; it is just the foundation of human capital. We ought to establish a scientific human capital concept, rationalize human capital investment, optimize human capital allocation, and consider human capital investment quality improvement as the priority of economic growth. Based on the above statistical analyses, the following suggestions are provided: (1) Establish scientific human capital concept, and emphasize on human capital quality; (2) Optimize education level, and innovate college cultivation mode; (3)Increase government subsidies, and formulate talent preferential policies;(4)Balance the investment quotas of production factors, and promote talent mobility.

\section{B. Emphasize financial geography, build multi-level financial system}

Generally speaking, the financial development in Kunming is in the "investment-driven" level, and it is forging toward "innovation-driven" level with the development of high-tech and the advance of reform. Therefore, it has become a mechanism in Kunming to optimize resource allocation efficiency. Meanwhile, in order to accelerate the economic development of Northwest in Yunnan, in addition to the centralization of State Policy Bank and the preference of credit policy, there should also be funds to provide money for the development of Northwest in Yunnan. The following suggestions are provided: (1)Establish technology mutual funds; (2)Create development funds of Northwest in Yunnan; (3)develop the industrial investment fund of Northwest in Yunnan. 


\section{Establish information capital network, create a good credit environment}

To develop credit capital, credit management system is an important precondition. Combining the establishment of social credit system, a series of credit management legal system need to be created. And the core purpose is to define and handle the relationship between government information openness and national economic security protection, trade secret confidential and credit information openness, consumer privacy protection and credit information openness; and accelerate the establishment of credit management legal system. In order to propel the financial development of each state in Yunnan, an information capital network should be established, and good credit environment needs to be created. The following are detailed suggestions: (1) Propel the establishment of social credit system; (2) Promote credit information resource sharing; (3)Actively cultivate credit rating industry; (4)Emphasize on the effect of credit capital; (5) Push the development of rural credit capital.

From table 8 after the rotation of the factor load matrix that can be found, the first principal factor in the state per capita GDP indicators have a lot of load, which defined as the financial development strength factor; The second main factor in the state per capita wage indicators are very Large load, which defined as the financial development of the driving force factor; The third main factor in the state financial institutions loan balance, the state postal business in the total length of the state financial institutions deposit balance, the state's natural science institutions engaged in scientific and technical personnel, Each state has a large load on these indicators, which defined as the financial development potential factor.

Through the construction of financial development comprehensive evaluation model $\mathrm{F}$, which gets factor comprehensive score of each state in Yunnan Province.

\section{Driving tourism investment, develop regional characteristic finance}

With the help of provincial tourism planning (one core city, one urban agglomeration, four industrial belts, five tourist areas, eight tourist corridors), and the tourist characteristics and development superiority of every periphery city, a horizontal alliance need to be formed to achieve complementary advantages and resource sharing; a multilevel and multipurpose regional tourism network need also to be created. It's important to increase tourism industry attraction, and create a financial "lowland effect" . At the early development stage, tourism attractions need large-scale investment and massive amount of funds. Bank entities should enhance cooperation, and support tourism with syndicated loans. Considering current situation of provincial tourism, the following suggestions are provided: (1) Highlight the construction of key scenic spots, and accelerate the cultivation of tourism market; (2) Optimize the integration of tourism resources, and extend tourism industry line; (3) Increase financial support, and improve financial service system; (4) Strengthen multi-coordinated linkage, and construct diversified investment and financing model.

\section{E. Prevent exchange rate risks, strengthen financial supervision}

For a great province of tourism in Yunnan, inadequate financial risk supervision may cause regional financial crisis and threaten the financial stability of the whole province. Among every states in Yunnan, the financial operation differences have also caused the financial risk level differences. Thus, it's extremely important to strengthen financial supervision and build effective financial supervision system; only in this way we ensure a healthy financial industry development for the Northwest in Yunnan and the whole Yunnan province. The following are the suggestions: (1) Implement financial assets valuation system; (2)Create financial institution rating system;(3) Utilize external audit; (4)Build financial risk-warning mechanism in Northwest of Yunnan.

\section{CONCLUSION}

Based on the relevant data from 2010 to 2016, we analyze the current situation of regional financial volume, regional financial structure and regional financial efficiency in Yunnan, it is found that the financial development is obviously different in every state of Yunnan province. Through the empirical analysis, we draw that the main factors influencing the regional development difference of the financial industry in Yunnan are economic base and human capital level, followed by investment and financing level, regional informatization level and geographical location. However, the influence of science and technology and transportation conditions are low. In view of the influencing factors, we propose the measures that should be taken by the relevant government departments and financial institutions in Yunnan Province, so as to enable the regional financial system to be coordinated and sustainable development, and improve the financial development level in Yunnan.

\section{REFERENCES}

[1] Li Zheng Hui,Hu Bi Feng.The differences and empirical studies of financial development in China's provinces[J].statistics and decision, 2014 (12): 154-157.

[2] Li Wen Qi.Regional disparity of rural financial development in China [J]. rural economy, 2014 (7): 74-78.

[3] Bu Hui,Liang Xiao Zhen ,Pi Li.Spatial statistical analysis of regional development in China's financial industry $[\mathrm{J}]$. systems engineering theory and practice, 2014, 34 (5): 1171-1180.

[4] Cheng Chun Lin,Hua Gui Hong.The dynamic change of Jiangsu's financial development difference: 2001-2011-analysis based on Theil index [J]. East China economic management, 2013,27 (11): 22-25.

[5] Xie Yun Liang,Liu Lei.Regional differences and causes of China's rural financial development [J]. research on economic issues, 2013 (6): 79-85.

[6] Zhao Xi.Regional difference, regional financial disparity and economic development imbalance-analysis from the perspective of spatial economics [J]. Hubei Social Sciences, 2015 (3): 69-73. 